\title{
Novel Mathematical Model for Kinetic of Weight Loss of Plastic Under Isothermal Conditions.
}

\author{
L.P.S. Rohitha ${ }^{1}$, S.S.N.Perera ${ }^{2}$ and M.A.B.Prashantha ${ }^{3}$ \\ ${ }^{1}$ University of Moratuwa, Department of Earth Resources Engineering. Sri Lanka, \\ ${ }^{2}$ University of Colombo, Research \& development Centre for Mathematical Modelling, Department of \\ Mathematics, Sri Lanka \\ ${ }^{3}$ University of Sri Jayewardenepura, Department of Chemistry. Sri Lanka
}

\begin{abstract}
Behaviour pattern of degradation of plastic material is very important in industrial applications. Activation energy is hindering factor in the degradation process of plastic materials. This is the very important in the selecting the plastic materials. In this study objective is activation energy could be predicted as the function of temperature and time. Experiment results of heated polypropylene plastic pieces $(3 \times 15 \mathrm{~cm})$ for $0-8$ hours have presented the effect of isothermal temperature. In this study the average weight loss range were 0.3 - $0.4 \%$ at end of 8 hours at $80,100,120,140^{\circ} \mathrm{C}$ temperature. In this generated model combination of arrahenious model new models. Order of $\boldsymbol{n}$ could be calculated using experimental data and using created model. Finally activation energy was expressed by the temperature and time parameters. Generated new model related to prediction of activation energy in the polypropylene plastic.
\end{abstract}

Keywards: Weight loss, polypropylene, Activation Energy

\section{Introduction}

The global production of plastic in year 2000 was reached to 150 million tons and the estimated yield of plastic waste was 105 million tons [1]. Plastic product consists polymer molecules, filler material, additives, processing aids, residual monomer, impurities and catalysts and other supportive substances used in polymerization processes and impurities in major and minor materials. Leaching of the non polymeric substances (NPS) in plastic has significant affected to pollution to ecosystem and develop heath problems [2]. Polypropylene becomes one of most useful thermoplastic material in petroleum era since its excellent cost/performance balance, versatile properties, good process ability and low density.In Sri Lanka 500,000 metric tons of virgin plastic are imported to the country $70 \%$ producing plastic products for local market and 30\% for export market[3].

Arrhenius equation and mass loss function based mathematical models have been developed for studying the kinetics of polymer degradation in a range of temperature from $25^{\circ} \mathrm{C}$ to $700^{\circ} \mathrm{C}$ using TGA [1521]. Arrhenius equation was found in 1910 for chemical reactions of liquid state, when rector's proprieties do not change with the time [4]. However in the degradation process rectors propertied are changes with time.

The equation (1) represents the isothermal kinetic models of polymer degradation as a multiplication of Arrhenius equation and mass loss functions [5].

$$
\frac{d \alpha}{d t}=K(T) F(\alpha)
$$

The equation (2) defines the rate constant $(K)$ at absolute temperate $(\mathrm{T})$ and the equation (3) defines mass loss function $F(\propto)$.

$$
\begin{aligned}
& K(T)=A e^{-\frac{E}{R T}} \ldots \\
& F(\alpha)=(1-\alpha)^{n}
\end{aligned}
$$

The terms A, E, R,T, $\alpha$ and $n$ are frequency factor (Arrhenius constant), activation energy, universal gas constant $\left(8.3134 \mathrm{Jmol}^{-1} \mathrm{~K}^{-1}\right)$, absolute temperature, mass loss and order of reaction respectively. The equation (4) defines $(\alpha)$, where $W_{o}, W t$ and $W_{f}$ are initial mass, the mass at time " $t$ " and final mass respectively.

$\alpha=\frac{\left(W_{0}-W_{t}\right)}{\left(w_{0}-w_{f}\right)}$

The substitution of equation (2) and (3) to the equation (1) yields the equation (5). It represents the rate of weight loss at the given movement at a given temperature.

$$
\frac{d \alpha}{d t}=(1-\alpha)^{n} A e^{-\frac{E}{R T}}
$$


Linearity of Arrhenius equation is limited to very narrow range of weight loss (0-0.4), (0.4-0.6), (0.60.9 ) when the range of loss of weight nearly up to zero to $0.3 \%$ as w/w\% [6]. It indicated low linearity of Arrhenius equation for the full range of weight $\operatorname{loss}(\alpha)$ from zero to 1.The objective of this study is to develop a mathematical model for kinetic of weight loss of plastic under isothermal condition below the melting point.

\section{Methodology}

Polypropylene based plastic boxes used in ice cream manufacturing industry was selected for investigating the mass loss behaviour at different temperatures. Dumbbell shapes samples were prepared using dumbbell cutter and average thickness of sample was $0.2 \mathrm{~mm}$. A set of samples was placed in oven set at a specific temperature for studying the mass loss under isothermal condition. Three samples were taken out at one hour intervals and placed in a desiccators allowed for cooling to room temperature over 24 hours to determine weight and density. The weight of samples were used to calculate average weight loss. Density measurements were obtained using density balance-(Model D125). The study was carried out four different isothermal temperatures at $100,120,140^{\circ} \mathrm{C}$.

\section{Theory}

The terms $\mathrm{A}$ and $\mathrm{E}$ in equation (5) are characteristic constant at constant temperature and hence the second component in the equation (5) represents the rate constant of weight loss process. The substitution of rate constant $(k)$ to the equation (5) and rearrangement yields the equation (6).

$$
\begin{aligned}
& k=A e^{-\frac{E}{R T}} \\
& \frac{d \alpha}{d t}=k(1-\alpha)^{n} \\
& {\left[\frac{1}{(1-\alpha)^{n}}\right] d \alpha=k d t}
\end{aligned}
$$

If $\mathrm{A}$ and $\mathrm{E}$ are time depending functions the integration of equation (6) is not possible without knowing the time dependency parameters of $k$.

The kinetic of weight loss of plastics depend on the amount of low molecular mass organic compounds and path length of microscopic channel system within the plastic matrix, strength of interactions, and segmental mobility of polymer chains. The formation of microscopic cavities and channels during the evaporation of volatile component will change the microscopic environment. It is assumed that the formation of microscopic cavities and channels facilitate the free movements of rest mass of volatile substances within the $\mathrm{w}_{\mathrm{o}}-\mathrm{w}_{\mathrm{f}}$ mass range.

The equation (7) is a rearrangement of equation (6) to express the rate constant as a product of rate of mass loss, $\left[\frac{d \alpha}{d t}\right]$ and $\left[\frac{1}{(1-\alpha)^{n}}\right]$

$$
\left[\frac{1}{(1-\alpha)}\right] \times\left[\frac{d \alpha}{d t}\right]=k^{\prime}
$$

If $n=1$,

$k^{\prime}=\left[\frac{1}{(1-\alpha)}\right] \times\left[\frac{d \alpha}{d t}\right]$

If $n=2$,

$k^{\prime}=\left[\frac{1}{(1-\alpha)}\right] \times\left[\frac{1}{(1-\alpha)}\right] \times\left[\frac{d \alpha}{d t}\right] \ldots$

If $n=3$,

$$
k^{\prime}=\left[\frac{1}{(1-\alpha)}\right] \times\left[\frac{1}{(1-\alpha)}\right] \times\left[\frac{1}{(1-\alpha)}\right] \times\left[\frac{d \alpha}{d t}\right] .
$$

The $\left[\frac{1}{1-\alpha}\right]$ represents $\frac{\left(W_{o}-W_{f}\right)}{\left(W_{t}-W_{f}\right)}$ and it can be defined as the total mass of low molar mass compounds to the unit mass of low molar mass compounds present at temperature T and time $t$. It is defined as $\emptyset$ in equation (11).

$$
\emptyset=\left[\frac{1}{1-\alpha}\right]
$$

The equation (7) can also be written as in equation (12), where $\mathrm{i}=\mathrm{m}-1$.

$$
k^{\prime}=\left[\frac{1}{1-\alpha}\right]^{i}\left[\frac{1}{1-\alpha}\right] \frac{d \alpha}{d t}
$$

The $\frac{d \alpha}{d t}$ in equation (12) represents instantaneous rate of weight loss. The product of $\left[\frac{1}{1-\alpha}\right]$ and $\frac{d \alpha}{d t}$ in equation

(12) is rearranged to yield the equation (13)

$\omega=\left[\frac{1-\alpha}{\left(\frac{d \alpha}{d t}\right)}\right]$. 
The $k^{\prime}$ in equation (14) function of time $\emptyset^{i}, \omega$ are function of time.

$$
k^{\prime}=\frac{\emptyset^{i}}{\omega}
$$

The value of $k^{\prime}$ in equation (14) represents the instantaneous state of the material at a unite time during the weight loss at a temperature $\mathrm{T}$. The formation of microscopic cavities during the weight loss is assumed to extent the path length and connectivity between microscopic channels.

It is assumed that the size of cavity is comparable with molecular volume of volatile substance caused for weight loss. The path length is defined as the distance to be moved through microscopic channel from the original location of low molar mass molecule to the interface between the substrate and surrounds. Heat is used at a point in order to break interactions and move the volatile molecules throughout the path length. Heat requirement at unit time during the weight loss is assumed to be increased.

The product of RT represents the thermal energy of one mole of substance in gas phases at temperature $\mathrm{T}$ and hence the product of $k^{\prime}$ and RT is assumed to be the instantaneous rate of thermal energy utilization for one mole of substance responsible to the weight loss. The equation (15) represents instantaneous rate of thermal energy utilization for one mole of low molar mass substance at weight loss. The unit of $E_{\text {ins }}^{i}$ is $\mathrm{j} \mathrm{mol}^{-1} \mathrm{~h}^{-1}$ or $\mathrm{j}$ $\mathrm{mol}^{-1} \mathrm{~s}^{-1}$.

$$
E_{\text {ins }}^{i}=\frac{\emptyset^{i}}{\omega} R T
$$

Instantaneous rate of thermal energy utilization is a function of microscopic environment of the

system during the weight loss. Hence, the equation (16) defines the rate of thermal energy utilization with time during the weight loss.

The effect of microscopic cavity formation and interconnecting to form microscopic channel system during the weight loss are assumed to be large change in microscopic environment of plastic texture in order to increase the randomness and path length of low molar mass volatile molecules within the microscopic channel system. The thermal energy utilization for the weight loss due to low moral mass substances in plastic material is assumed to be in exponentially increasing order with the weight loss. The collisions between volatile molecules and air in the microscopic channels may retard the molecular movements of volatile molecules. Hence, these factors are significant to exponential decay of the amplitude of instantaneous rate of weight loss with the cavity formation. Therefore instantaneous microscopic changes significantly affect to the instantaneous rate of thermal energy utilization during the mass loss process at temperature $\mathrm{T}$. Therefore exponential relationship can be express between $E_{\text {ins }}^{i}$ and $(1-\alpha)^{\gamma}$. It can be express in equation (17) as follows. The exponential term of equation (17) represents unit less quantity and hence the unit of $\varphi$ is the unit of $E_{\text {ins }}^{i}$ (j $\mathrm{mol}^{-1} \mathrm{~h}^{-1}$ or j mol $\mathrm{s}^{-1}$ ).

$E_{\text {int }}^{i}=\varphi e^{\varepsilon(1-\alpha)^{\gamma}}$

The terms $\varepsilon, \varphi, \& \gamma$ are characteristic constants for the plastic material in order to determine $E_{\text {ins }}^{i}$ at a given $\alpha$ and temperature. The equation (15) and (17) are combined to yield the equation (17.1)

$\frac{\emptyset^{i}}{\omega} R T=\varphi e^{\varepsilon(1-\alpha)^{\gamma}}$

$$
\ln \left[\frac{R T \emptyset^{i}}{\omega}\right]=\varepsilon(1-\alpha)^{\gamma}+\ln \varphi
$$

Equation (18) shows a liner relationship at a specific value of $i$ and $\gamma$. The gradient and intercept of the linear plot of $\ln \left[\frac{R T \phi^{i}}{\omega}\right]$ vs $(1-\alpha)^{\gamma}$ at the specific values $i$ and $\gamma$ represent $\varepsilon$ and $\ln (\varphi)$ respectively. The following algorithm is used to calculate the specific values of $i$ and $\gamma$ using computer program.

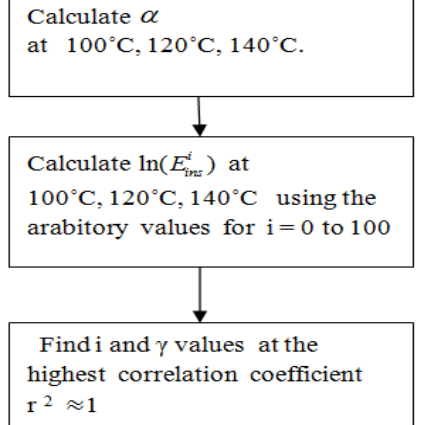

Figure1 - Algorithm related to $i$ and $\gamma$ determination computer program 
The numerical value of $\mathrm{i}$ and $\gamma$ are substituted to equation 17.1 to derive the rate low of weight loss under isothermal condition. The substitution of equation 13 to the equation 17.1 yields the equation 18.1 .

$$
\frac{\mathrm{d} \alpha}{\mathrm{dt}}=\frac{\varphi}{\mathrm{RT}} \emptyset^{-\mathrm{n}} \mathrm{e}^{\epsilon(1-\alpha)^{\gamma}}
$$

The $\left[\frac{\varphi}{\mathrm{RT}}\right]$ represents the rate constant, $\mathrm{k}_{\mathrm{T}}$ in equation 18.1, of weight under isothermal condition when the $\mathrm{n}$ and $\gamma$ are know.

$$
\frac{\mathrm{d} \alpha}{\mathrm{dt}}=\mathrm{k}_{\mathrm{T}} \emptyset^{-\mathrm{n}} \mathrm{e}^{\epsilon(1-\alpha)^{\gamma}}
$$

\section{Result And Discussion}

Figure 2 shows the effect of heating temperature and number of heating-time on the bulk density of commercial polypropylene product at room temperature.

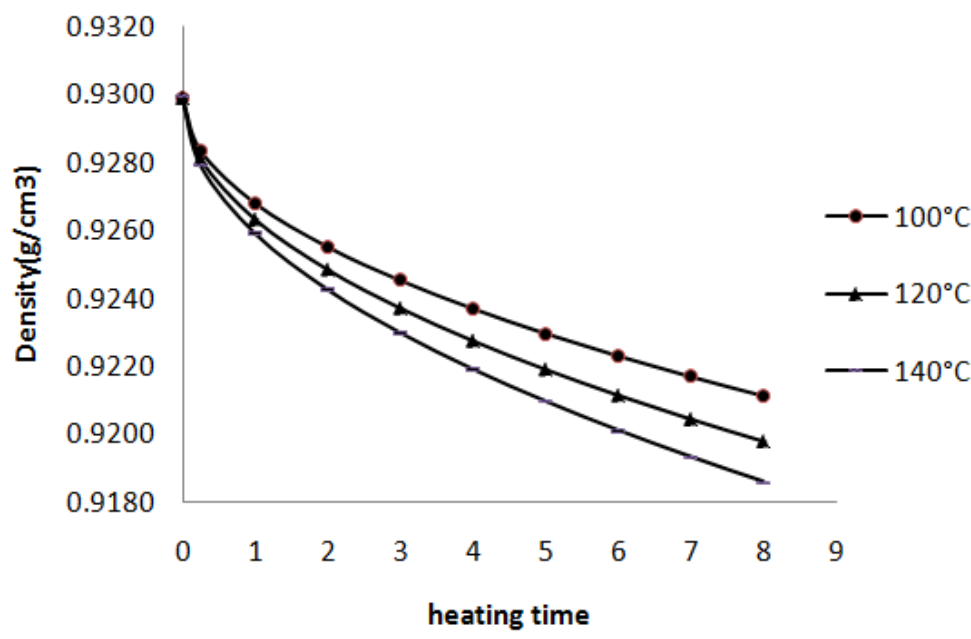

Figure 2: Plot of Bulk Density $\left(\mathrm{g} / \mathrm{m}^{3}\right)$ of commercial polypropylene vs heating time.

As shown in figure 2, the density of the sample at room temperature at the end of the successive hearting time has exponentially decreased. The figure 3 shows the weight loss of samples at the end of the hearting time. The expansion of samples and evaporation of volatile substances take please during the heating time. Weight loss and cavity formation during the heating time have caused to lower the density of sample. Contractions take place during the cooling to room temperature. As show in the figure 2, the decreasing trend of density of sample at room temperature at the end of the heating and cooling is due to the prominent effect of the volume of the microscopic cavity over the contraction. Weight loss increases in parabolic pattern with the hearting time. It indicates the development of barriers for weight loss with the hearting time.

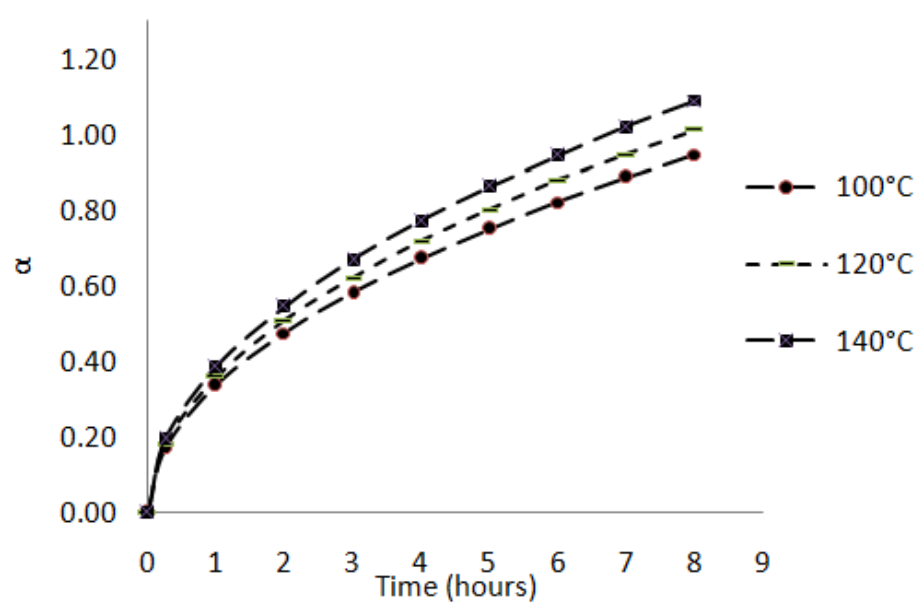

Figure 3: Weight loss at four different temperatures with hearting time. 
Figure 4 shows the liner relationship between $\ln \left[\frac{R T \emptyset^{i}}{\omega}\right]$ and $(1-\alpha)^{\gamma}$ as given equation (18) at 80,100,120, $140^{\circ} \mathrm{C}$ temperature. Table 1 shows the characteristic values for i, $\gamma, \varepsilon$ and $\varphi$ at the four different temperatures at the highest of correlation coefficient. When the $\ln \left[\frac{R T \phi^{i}}{\omega}\right]$ shows a liner relationship with $(1-\alpha)^{\gamma}$.

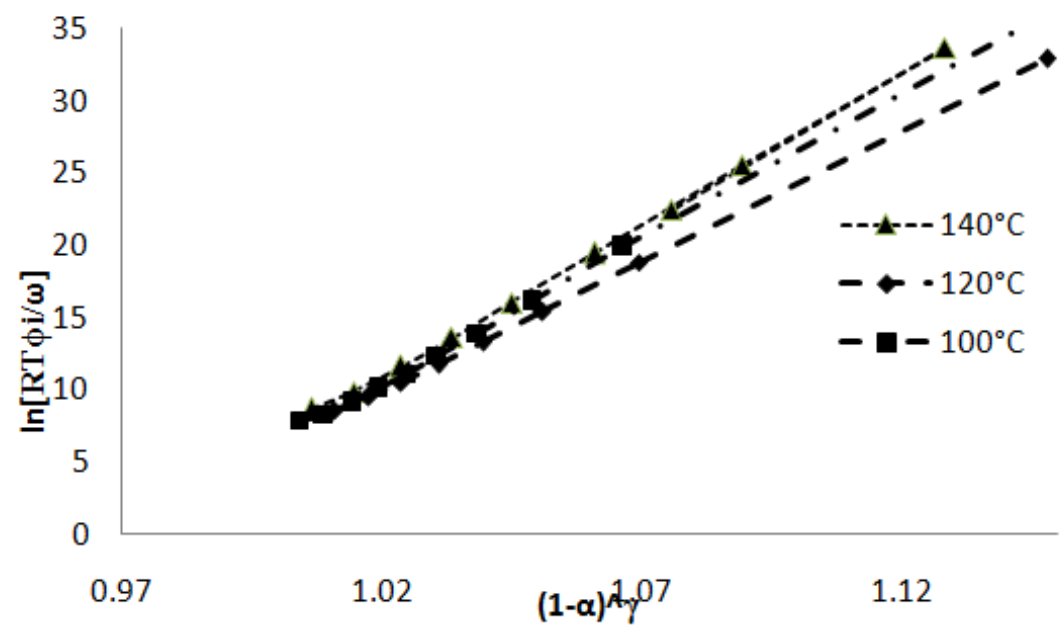

Figure 4 shows the liner relationship between $\ln \left[\frac{R T \phi^{i}}{\omega}\right]$ and $(1-\alpha)^{\gamma}$ at $80,100,120,140^{\circ} \mathrm{C}$ temperature.

Table 1: shows the characteristic values for $i, \gamma, \varepsilon$ and $\varphi$ at the four different temperature.

\begin{tabular}{|l|l|l|c|l|l|l|l|}
\hline $\mathrm{T}$ & $\mathrm{n}$ & $\mathrm{i}=\mathrm{m}-1$ & $\gamma$ & $\varepsilon$ & $\ln \varphi$ & $\mathrm{R}^{2}$ & Equation \\
\hline $100^{\circ} \mathrm{C}$ & 6 & 5 & -0.022 & 199.2 & -192.8 & 0.99831 & $\ln \left[\frac{3101.1}{(1-\alpha)^{5}} \frac{d \alpha}{d t}\right]=199.2(1-\alpha)^{-0.022}-192.8$ \\
\hline $120^{\circ} \mathrm{C}$ & 6 & 5 & -0.025 & 177.3 & -170.8 & 0.99511 & $\ln \left[\frac{3267.4}{(1-\alpha)^{5}} \frac{d \alpha}{d t}\right]=177.3(1-\alpha)^{-0.025}-170.8$ \\
\hline $140^{\circ} \mathrm{C}$ & 7 & 6 & -0.03 & 208 & -201.2 & 0.99688 & $\ln \left[\frac{3433.7}{(1-\alpha)^{6}} \frac{d \alpha}{d t}\right]=208(1-\alpha)^{-0.03}-201.2$ \\
\hline
\end{tabular}

Integration of equation 18.2 using $\mathrm{i}$ and $\gamma$ at $120^{\circ} \mathrm{C}$

$$
\int_{0}^{\alpha} \frac{1}{(1-\alpha)^{6} e^{\frac{-177.7}{(1-\alpha)^{0.025}}}} d \alpha=\int_{0}^{t} k t d t
$$

Integration of left hand side of the equation (18.3) is very complicated and too long. Thus left hand side equation was separated into two parts and integration was done as follows using MATLAB mupad software. Expansion of first part is given below

$\frac{1}{(1-\alpha)^{6}}=a_{0}+a_{1} x+a_{2} x^{2}+a_{3} x^{3}+a_{4} x^{4}+a_{5} x^{5}+O\left(x^{6}\right)$

Where;

$a_{0}=1, \quad a_{1}=6 \quad a_{2}=21 \quad a_{3}=56 \quad a_{4}=126 \quad a_{5}=252$

$O=$ rest function

$\frac{1}{(1-\alpha)^{6}}=1+6 \mathrm{x}+21 x^{2}+56 x^{3}+126 x^{4}+252 x^{5}+0\left(x^{6}\right)$

Expansion of second part is given below

$\frac{1}{e^{\frac{-177.7}{(1-\alpha)^{0.025}}}}=b_{0}+b_{1} x+b_{2} x^{2}+b_{3} x^{3}+b_{4} x^{4}+b_{5} x^{5}+G\left(x^{6}\right)$

Where;

$b_{0}=6.69684 \times 10^{-78}, b_{1}=-2.97507 \times 10^{-77}, b_{2}=5.08366 \times 10^{-77}$
$b_{3}=-4.04151 \times 10^{-77}, b_{4}=1.3522 \times 10^{-77}, b_{5}=-6.88022 \times 10^{-79}$
$G=$ rest fuction

$$
\begin{gathered}
\frac{1}{e^{\frac{-177.7}{(1-\alpha)^{0.025}}}=6.69684 \times 10^{-78}-2.97507 \times 10^{-77} x+5.08366 \times 10^{-77} x^{2}-4.04151 \times 10^{-77} x^{3}} \\
+1.3522 \times 10^{-77} x^{4}-6.88022 \times 10^{-79} x^{5}+G\left(x^{6}\right)
\end{gathered}
$$


The product of equation(A) and(B) yields the overall term to be integrated of the equation 18.3.

$\frac{1}{(1-\alpha)^{6} e^{\frac{-177.7}{(1-\alpha)^{0.025}}}}=\left[a_{0}+a_{1} x \ldots .+O\left(x^{6}\right)\right] \times\left[b_{0}+b_{1} x+\cdots+b_{5} x^{5}+G\left(x^{6}\right)\right]$
$\frac{1}{(1-\alpha)^{6} e^{\frac{-1777.7}{(1-\alpha)^{0.025}}}}=c_{0}+c_{1} x+c_{2} x^{2}+c_{3} x^{3}+c_{4} x^{4}+c_{5} x^{5}+H\left(x^{6}\right) \ldots \ldots \ldots \ldots(\mathrm{C})$

Where;

$c_{0}=6.69684 \times 10^{-78}, c_{1}=1.04303 * 10^{-77}, c_{2}=1.29659 * 10^{-77}$

$c_{3}=1.48622 * 10^{-77}, c_{4}=1.63608 * 10^{-77}, \quad c_{5}=1.75883 * 10^{-79}$

$H=$ rest fuction

$\frac{1}{(1-\alpha)^{6} e^{\frac{-177.7}{(1-\alpha)^{0.025}}}}=6.6968 \times 10^{-78}+1.0430 \times 10^{-77} x+1.2965 \times 10^{-77} x^{2}+1.4862+10^{-77} x^{3}+$

$1.6360 \times 10^{-77} x^{4}+1.7588 \times 10^{-77} x^{5}++H\left(x^{6}\right)$

The integration of right side of equation $\left(\mathrm{C}^{\prime}\right)$ without the rest function gives approximate solution to the integration of left side of the same equation.

$\int_{0}^{\alpha} \frac{1}{(1-\alpha)^{6} e^{\frac{-177.7}{(1-\alpha)^{0.025}}}} d \alpha=\left(2.9313 x^{6}+3.2721 x^{5}+3.7155 x^{4}+4.3219 x^{3}+5.2151 x^{2}+6.69684 x\right) *$

$10-78=\mathrm{k}_{120} \mathrm{t}$.

Equation (19) can be rearranged in order to yield equation (19.1), where $K_{120}^{\prime \prime}$ is $\frac{K_{120}}{10^{-78}}$. The higher order of $\alpha$ in the integration solution given in equation (19) are neglected and the solution is considered to limit first two terms of weight loss $(\alpha)$. The equation (23) is the integration solution of Arrhenius equation for the weight loss of plastics.

The highest correlation for the linearity of Arrhenius equation was found to be at first order (equation (23)) with respect to the $(1-\alpha)$ at three different temperatures. The plot of $[-\ln (1-\alpha)]$ with time in figure 5 shows the deviation of Arrhenius equation when the weight loss is closes to unity .

$-\ln (1-\alpha)=k t$ (23).

Table 2: Gives Simplified equations with their coefficients.

\begin{tabular}{|l|l|c|c|}
\hline Temperature & Equation & $\mathrm{K}_{\mathrm{T}}^{\prime \prime}$ & $\mathrm{K}_{\mathrm{T}}$ \\
\hline $100^{\circ} \mathrm{C}$ & $16.90 x+13.56 x^{2}=\mathrm{K}_{100^{\circ} \mathrm{C} \ldots \ldots(20) .}$ & $3.849 \times 10^{-88}$ & $5.9773 \times 10^{-88}$ \\
\hline $120^{\circ} \mathrm{C}$ & $6.70 x+5.22 x^{2}=\mathrm{K}_{120^{\circ} \mathrm{C} \cdots \cdots \ldots . .(21) .}$ & $1.508 \times 10^{-78}$ & $2.033 \times 10^{-78}$ \\
\hline $140^{\circ} \mathrm{C}$ & $4.64 x+1.76 x^{2}=\mathrm{K}_{140^{\circ} \mathrm{C} \cdots \cdots \cdots \ldots . .(22) .}$ & $1.008 \times 10^{-91}$ & $1.3415 \times 10^{-91}$ \\
\hline
\end{tabular}

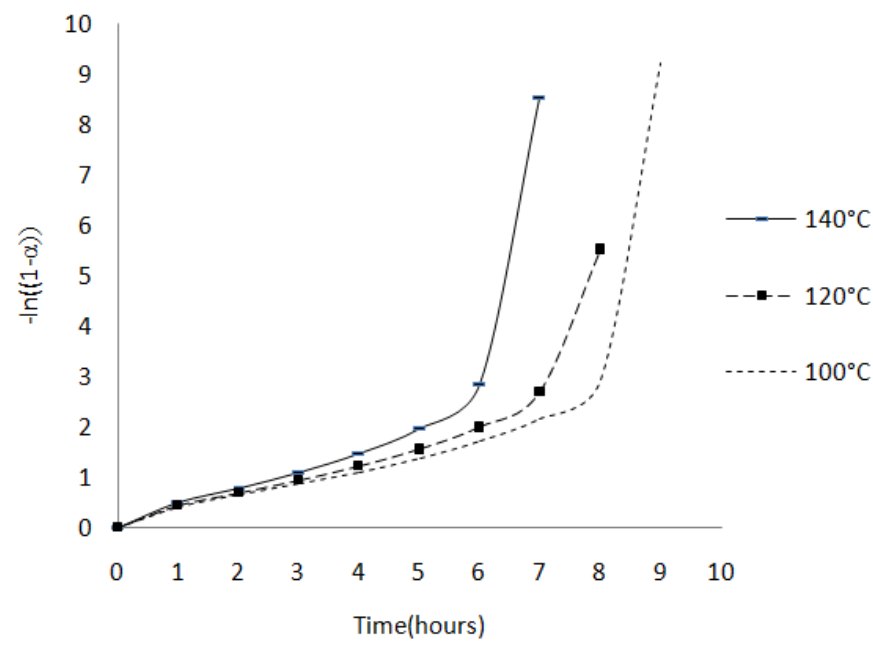

Figure 5:-The plot of $[-\ln (1-\alpha)]$ with time at different temperatures .

Table 2 shows the comparison of experimental time with the time calculated by proposed model at $99 \%$ and 95\% level of confidential interval and time calculated by the Arrhenius equation when the heating temperature is $80^{\circ} \mathrm{C}$.

Table 3 shows the comparison of experimental time with the time calculated by proposed model and the Arrhenius equation when the heating temperatures of $100,120,140^{\circ} \mathrm{C}$. The rate constant $\frac{\varphi}{R T}$ calculated from the in equation (18.1) 
Novel Mathematical Model for Kinetic of Weight Loss of Plastic Under Isothermal Conditions.

Table 3- Compression of time taken to reach the given values of $\alpha$ at $100^{\circ} \mathrm{C}, 120^{\circ} \mathrm{C}, 140^{\circ} \mathrm{C}$.

\begin{tabular}{|c|c|c|c|}
\hline & \multicolumn{3}{|l|}{ Time(hours) } \\
\hline & \multirow[t]{2}{*}{ Experimental } & \multirow[t]{2}{*}{ Proposed model } & \multirow{2}{*}{$\begin{array}{l}\text { Arrhenius } \\
\text { equation }\end{array}$} \\
\hline$\alpha$ for $100^{\circ} \mathrm{C}$. & & & \\
\hline 0 & 0 & 0 & 0.0 \\
\hline 0.3347 & 1 & 1.3 & 0.4 \\
\hline 0.4733 & 2 & 2.1 & 0.6 \\
\hline 0.5797 & 3 & 2.8 & 0.9 \\
\hline 0.6693 & 4 & 3.5 & 1.1 \\
\hline 0.7483 & 5 & 4.2 & 1.4 \\
\hline 0.8198 & 6 & 4.9 & 1.7 \\
\hline 0.8854 & 7 & 5.6 & 2.8 \\
\hline 0.9466 & 8 & 6.3 & 2.9 \\
\hline \multicolumn{4}{|l|}{$\alpha$ for $120^{\circ} \mathrm{C}$. } \\
\hline 0 & 0 & 0 & 0 \\
\hline 0.3521 & 1 & 1.6 & 0.4 \\
\hline 0.4980 & 2 & 2.5 & 0.7 \\
\hline 0.6099 & 3 & 3.4 & 0.9 \\
\hline 0.7043 & 4 & 4.3 & 1.2 \\
\hline 0.7874 & 5 & 5.2 & 1.5 \\
\hline 0.8626 & 6 & 6.1 & 2 \\
\hline 0.9317 & 7 & 7.0 & 2.7 \\
\hline 0.9960 & 8 & 7.9 & 5.5 \\
\hline \multicolumn{4}{|l|}{$\alpha$ for $140^{\circ} \mathrm{C}$. } \\
\hline 0 & 0 & 0 & 0 \\
\hline 0.3742 & 1 & 1.4 & 0.49 \\
\hline 0.5292 & 2 & 2.1 & 0.79 \\
\hline 0.6481 & 3 & 2.7 & 1.1 \\
\hline 0.7483 & 4 & 3.3 & 1.5 \\
\hline 0.8367 & 5 & 3.8 & 2.0 \\
\hline 0.9165 & 6 & 4.4 & 2.9 \\
\hline 0.9899 & 7 & 4.8 & 8.5 \\
\hline 1.0000 & 8 & 5.0 & 11.5 \\
\hline
\end{tabular}

The gradient of the plot of $\left(a x+b x^{2}\right)$ with time gives the $E_{T}^{\prime \prime}$ to cal calculate the magnitude of $\mathrm{K}_{\mathrm{T}}$. The $\mathrm{K}_{\mathrm{T}}$ values can b calculated from $\frac{\varphi}{R T}$ as shown in equation (18.1). Table 4 shows the comparison between $K_{T}$ values obtained from the gradient of the plot of $\left(a x+b x^{2}\right)$ with the time and calculated from $\frac{\varphi}{R T}$

Table 4 : Comparison between $K_{T}$ values obtained from the gradient of the plot.

\begin{tabular}{|l|c|c|}
\hline Temperature & $K_{T}$ from the gradient & $K_{T}$ from $\frac{\varphi}{R T}$ \\
\hline $100^{\circ} \mathrm{C}$ & $3.849 \times 10^{-88}$ & $5.9773 \times 10^{-88}$ \\
\hline $120^{\circ} \mathrm{C}$ & $1.508 \times 10^{-78}$ & $2.033 \times 10^{-78}$ \\
\hline $140^{\circ} \mathrm{C}$ & $1.008 \times 10^{-91}$ & $1.3415 \times 10^{-91}$ \\
\hline
\end{tabular}

\section{Conclusions}

A model is developed to explain the kinetic of weight loss of plastic in full range of $\alpha$ from 0 to 0.9 . Arrhenius fist order kinetics is limited to narrow range of $\alpha$. The basis of model is formation of microscopic cavities and channels within the matrix of plastics during the weight loss. The model is tested using commercial polypropylene product (ice cream box) plastic exposing to $100^{\circ} \mathrm{C}, 120^{\circ} \mathrm{C}$ and $140^{\circ} \mathrm{C}$ temperatures. Kinetic equation derived from the model shows polynomial relationship of weight loss with time. It is approximated to get a simplified equation in $a x+b x^{2}=K_{T}^{\prime \prime} t$ to calculate the time required to reach the given weight loss. The rate constant calculated from $\frac{\varphi}{R T}$

\section{References}

[1]. Moinuddin., S , Mohammad M,R, Muhammad., S. R, Mohammad, M., Polypropylene Waste Plastic into Light Fractional Gasoline Grade Fuel for Vehicle by using Two Step Thermal Processes, Int. J. Forest, Soil and Erosion, 2012 2 (4): 186-191,

[2]. Al-Furhood, J. A., Alsewailem, F. D. , Almutabaqani, L. A., Activation Energy for the pyrolysis of polymer wastes., Eur. Chem. Bull., 2014, 3(1), 93-97

[3]. Gersten J, Fainberg V, Hetsroni G, Shindler Y. Kinetic study of the thermaldecomposition of polypropylene. oil shale and their mixture. Fuel 2000;79(13):1679-1686.

[4]. Arao Y, Nakamura S, Tomita Y, Takakuwa K, Umemura T, Tanaka T. Improvement on fire retardancy of wood flour/polypropylene composites using various fire retardants. Polym Degrad Stab 2014;100(1):79-85.

[5]. DiNenno PJ, Drysdale D, Beyler CL, Walton WD, Custer RLP, Hall JR, Watts JM. SFPE Handbook of Fire Protection Engineering. 3rd ed. Bethesda: National Fire Protection Association; 2002. 1604 p. 
[6]. Xu ZZ, Huang JQ, Chen MJ, Tan Y, Wang YZ. Flame retardant mechanism of an efficient flame retardant polymeric synergist with ammonium polyphosphate for polypropylene. Polym Degrad Stab 2013;98(10):2011-2020.

[7]. Jiang W, Hao J, Han Z. Study on the thermal degradation of mixtures of ammonium polyphosphate and a novel caged bicyclic phosphate and their flame retardant effect in polypropylene.Polym Degrad Stab 2012;97(4):632-637.

[8]. Enescu D, Frache A, Lavaselli M, Monticelli O, Marino F. Novel phosphorous-nitrogen intumescent flameretardant system. Its effects on flame retardancy and thermal properties of polypropylene. Polym Degrad Stab 2013;98(1):297-305.

[9]. Chen XS, Yu ZZ, Liu W, Zhang S. Synergistic effect of decabromodiphenyl ethane and montmorillonite on flame retardancy of polypropylene. Polym Degrad Stab 2009;94(9):1520-1525.

[10]. Chien JCW, Kiang JKY. Polymer Reaction. 9. Effect of Polymer-Bound Chromium on Oxidative Pyrolysis of Poly(propylene). Macromol 1980;13(2):280-288.

[11]. [effery D. P, Sergey. V, Charles A. W, Kinetics of the Thermal and Thermo-Oxidative Degradation of Polystyrene, Polyethylene and Poly(propylene), Macromol. Chem. Phys. 2001, 202, 775-784

[12]. Tsuchiya,Y. Sumi, K. , J. Polym. Sci.A, 1969, 7, 1599.

[13]. David.C, "Thermal Degradation of Polymers", in: Comprehensive Chemical Kinetics, vol. 14, C. H. Bamford, C. F. H. Tipper, Eds., Elsevier, Amsterdam 1975, p. 1

[14]. Tsuchiya,Y. Sumi, K. , J. Polym. Sci. A 1968, 6, 415.

[15]. Kissinger, H. E., Anal. Chem., 1957, 29, 1702-1706.

[16]. Flynn, J. H., Wall, L. A., J. Polym. Sci. Part B: Polym. Lett., 1966,4, 323 -328.

[17]. Friedman, H. L., J. Polym. Sci. Part C, 1965, 6, 183-195.

[18]. Van Krevelen, D. W., Heerden, C. V., Huntjens, F. J., Fuel, 1951,30, 253

[19]. Coats, A. W., Redfern, J. P., J. Polym. Sci. Part B: Polym. Lett., 1965, 3, 917-920.

[20]. Reich, L., J. Polym. Sci. Part B: Polym. Lett., 1964, 2, 621-623.

[21]. Reich, L., J. Polym. Sci. Part B: Polym. Lett., 1965, 3, 231-234.

[22]. Nanocomposite., Vyazovkin,S, Dranca,I., Fan,X., Advincula.,R, Kinetics of the Thermal and Thermo-Oxidative Degradation of a Polystyrene-Clay, Macromol. Rapid Commun. (2004), 25, pp498-503. 